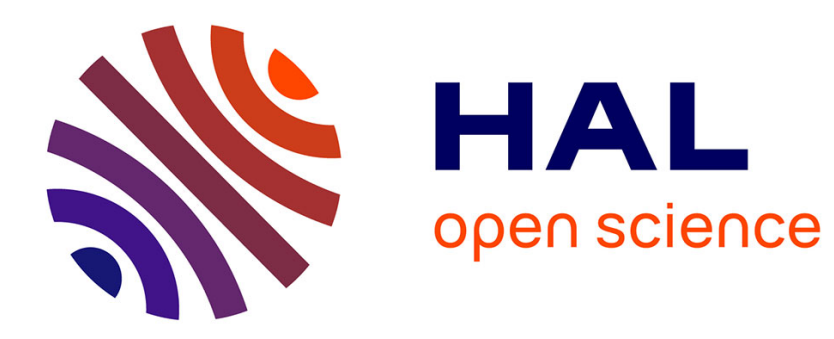

\title{
Informational Cascades: A Mirage?
}

Markus Spiwoks, Kilian Bizer, Oliver Hein

\section{To cite this version:}

Markus Spiwoks, Kilian Bizer, Oliver Hein. Informational Cascades: A Mirage?. Journal of Economic Behavior and Organization, 2008, 67 (1), pp.193. 10.1016/j.jebo.2007.06.005 . hal-00598265

\section{HAL Id: hal-00598265 \\ https://hal.science/hal-00598265}

Submitted on 6 Jun 2011

HAL is a multi-disciplinary open access archive for the deposit and dissemination of scientific research documents, whether they are published or not. The documents may come from teaching and research institutions in France or abroad, or from public or private research centers.
L'archive ouverte pluridisciplinaire HAL, est destinée au dépôt et à la diffusion de documents scientifiques de niveau recherche, publiés ou non, émanant des établissements d'enseignement et de recherche français ou étrangers, des laboratoires publics ou privés. 


\section{Accepted Manuscript}

Title: Informational Cascades: A Mirage?

Authors: Markus Spiwoks, Kilian Bizer, Oliver Hein

PII: $\quad$ S0167-2681(07)00142-4

DOI: $\quad$ doi:10.1016/j.jebo.2007.06.005

Reference: $\quad$ JEBO 2123

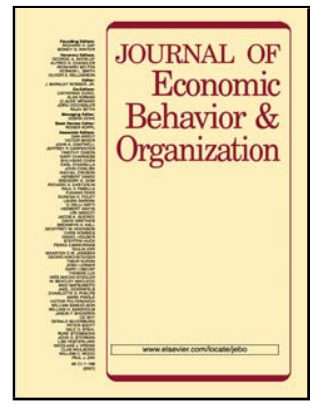

To appear in: Journal of Economic Behavior \& Organization

Received date: $\quad$ 5-5-2006

Revised date: $\quad 20-6-2007$

Accepted date: $\quad$ 20-6-2007

Please cite this article as: Spiwoks, M., Bizer, K., Hein, O., Informational Cascades: A Mirage? Journal of Economic Behavior and Organization (2007), doi:10.1016/j.jebo.2007.06.005

This is a PDF file of an unedited manuscript that has been accepted for publication. As a service to our customers we are providing this early version of the manuscript. The manuscript will undergo copyediting, typesetting, and review of the resulting proof before it is published in its final form. Please note that during the production process errors may be discovered which could affect the content, and all legal disclaimers that apply to the journal pertain. 


\title{
Informational Cascades: A Mirage?
}

\author{
Markus Spiwoks, Kilian Bizer, and Oliver Hein
}

\section{Corresponding Author:}

Prof. Dr. Markus Spiwoks

Wolfsburg University of Applied Sciences

Faculty of Business Administration

Chair in Finance

Robert-Koch-Platz 10-14

D-38440 Wolfsburg

Germany

Phone: +49-5361-83-1511

Fax: +49-5361-83-1502

Mobil: +49-173-65 15835

m.spiwoks@fh-wolfsburg.de

Prof. Dr. Kilian Bizer

Göttingen University

Faculty of Economics

Chair in Economic Policy

Platz der Göttinger Sieben 3

D-37073 Göttingen

Germany

bizer@wiwi.uni-goettingen.de

Ph.D. candidate Oliver Hein

Frankfurt University

Faculty of Business Administration

Chair in Information Systems

D-60054 Frankfurt

Germany

ohein@is-frankfurt.de 


\title{
Informational Cascades: A Mirage?
}

\begin{abstract}
Experimental research found contradictory results regarding the occurrence of informational cascades. Whereas Anderson and Holt (1997) confirmed the model of Banerjee (1992), and Bikhchandani et al. (1992) through lab tests, Huck and Oechssler (2000) came to contradictory results on crucial issues. This article presents experimental evidence supporting further doubts concerning "Bayesian" informational cascades: Just under two thirds of all decisions are characterized by an excessive orientation towards the private signal, and only a small number of the subjects $(<6 \%)$ make rational decisions systematically and consistently.
\end{abstract}

JEL classification: C91; D82

Keywords: Informational cascades; Experiments; Bayes' rule 
Rational herding and the precise circumstances under which it can arise have been studied by economists for around 70 years. ${ }^{1}$ The theory of informational cascades put forward by Banerjee (1992) and Bikhchandani et al. (1992) has enlivened this debate considerably. Particular attention has been paid in this context to herds that occur because subjects draw conclusions about the private signals of their predecessors on the basis of their actions and then take into account the reliability of their own and their predecessors' private signals and the a priori probability before finally making a rational decision by correctly using Bayes' rule. $^{2}$ This combination of circumstances will be referred to here as "Bayesian" informational cascades. $^{3}$

The first to present experimental evidence were Anderson and Holt (1997). According to them, "Bayesian" informational cascades occur regularly. ${ }^{4}$ Huck and Oechssler (2000), however, come to a different result. According to their understanding, the correct use of Bayes' rule is annulled by a systematic overrating of the respective private signals. This study investigates this contradiction.

\section{Experimental Design}

Each subject has to solve three tasks (Table 1). ${ }^{5}$ Let $A$ and $B$ denote the possible decisions, $a$ and $b$ be possible signals, and $\alpha$ and $\beta$ possible states of the world. The subjects have to decide between two alternative actions $A$ and $B . \alpha$ has an a priori probability of 0.49 and $\beta$ of 0.51 . They are informed which private signal ( $a$ or $b$ ) they have, how good the reliability of their private signal $(q)$ is, and how good the reliability of their predecessors' private signal is

\footnotetext{
${ }^{1}$ The two approaches of reputational herding and investigative herding date back to Keynes (1936).

${ }^{2} \mathrm{As}$ in the famous restaurant example used by Banerjee.

${ }^{3}$ This specification is necessary, as the concept of informational cascades put forward by Banerjee and by Bikhchandani et al. was initially used as a generic term for various explanatory approaches (e.g. sanctions on deviants, positive pay-off externalities, conformity preference).

${ }^{4}$ Hung and Plott (2001), Sgroi (2003) and Celen and Kariv (2004) analyze various model extensions. Partly explicitly, partly at least with regard to various marginal aspects, these studies support the results of Anderson and Holt

${ }^{5}$ The tasks are similar to the study of Huck and Oechssler. See Appendix A for the text of the tasks. Appendix $\mathrm{C}$ for detailed solution methods. Appendices are available on the JEBO website.
} 
(p). Finally they get to know which decisions their predecessors made. They are also told that all predecessors have exactly one private signal and have made rational decisions. Then they have to decide between actions $A$ and $B$.

Table 1

The three decision tasks

\begin{tabular}{llllll}
\hline & $\begin{array}{l}\text { Previous } \\
\text { decisions }\end{array}$ & $p$ & Signal & $q$ & $\begin{array}{l}\text { Rational } \\
\text { action }\end{array}$ \\
\hline Task 1 & $B$ & 0.80 & $a$ & 0.80 & $B$ \\
Task 2 & $A B B$ & 0.65 & $a$ & 0.65 & $B$ \\
Task 3 & $A A$ & 0.60 & $b$ & 0.65 & $A$ \\
\hline
\end{tabular}

With an a priori probability for $\beta=0.51$ and for $\alpha=0.49$.

These three decision-making situations have the clear advantage that they allow a distinct differentiation as to whether the subjects act according to Anderson and Holt, or according to Huck and Oechssler's interpretation. The subjects either make a rational decision in the sense of "Bayesian" informational cascades, or they trust their own private signal.

This clear distinction, which for the first time allows a clear discrimination between the two stated explanation patterns, is an important advance. To a considerable degree, both the analyses of Anderson and Holt and the study of Huck and Oechssler present decision-making situations in which the strict orientation towards one's own private signal leads to the same decision as an inference of the private signals of the predecessors and, based on this, a rational use of Bayes' rule.

Table 2

The distinction between the two explanatory patterns

\begin{tabular}{lcc}
\hline & $\begin{array}{c}\text { Solution that obtains by } \\
\text { rational decision-making }\end{array}$ & $\begin{array}{c}\text { Solution that obtains by strong } \\
\text { overweighting of the private signal }\end{array}$ \\
\hline Task 1 & $B$ & $A$ \\
Task 2 & $B$ & $A$ \\
Task 3 & $A$ & $B$ \\
\hline
\end{tabular}


227 subjects took part in six sessions with respective totals of 55, 50, 46, 37, 24 and 15 persons. In each of the six sessions the subjects were divided into three groups. These groups varied with regard to the order in which the tasks had to be solved. All subjects were students at the Wolfsburg University of Applied Sciences who study business administration. None of them had any experience of experimental research, and all had a thorough education in the calculus of probability. The use of a pocket calculator was allowed. There was no payment for participation in this experiment. Those subjects who correctly solve tasks received bonus points for a later exam. ${ }^{6}$

\section{Results}

Table 3 summarizes the results of the six sessions. "R" (for "Right") marks those decisions that can be called correct in the sense of a rational decision given the deduction of the private signals of the predecessors and the correct use of Bayes' rule. Thus "R" marks all those decisions that confirm the approach of Anderson and Holt. "W" (for "Wrong") marks those decisions which are not based on rationale but rather follow the person's own private signal. Thus "W" highlights all those decisions which confirm Huck and Oechssler's approach.

In total, the subjects made 681 decisions (see Table 3). Only 248 of them, or $36 \%$, were answered correctly in the rational sense. 433 decisions were wrong, so in $64 \%$ of all decisions the subjects either failed to draw conclusions from their predecessors' decisions about their private signals, did not correctly use Bayes' rule, and/or based their decisions on completely different aspects.

\footnotetext{
${ }^{6}$ For the effect of such incentives see Selten et al. (2003, p. 22). Those subjects who correctly solve all tasks receive 15 bonus points for a later exam (five bonus points for each correctly solved task). Other students were asked how much 15 bonus points for a later exam were worth to them, were they able to buy the 15 bonus points. The 42 students asked gave numbers between $€ 25$ and $€ 200$. The average was $€ 72.45$.
} 
Table 3

Summary of the results of the whole study

\begin{tabular}{|c|c|c|c|c|c|c|c|c|c|}
\hline & & & G & $\mathrm{r}$ & & $\mathrm{p}$ & & & \\
\hline & & \multicolumn{2}{|c|}{1} & \multicolumn{2}{|c|}{2} & \multicolumn{2}{|c|}{3} & \multicolumn{2}{|c|}{$\sum$} \\
\hline \multirow{4}{*}{$=$} & & $\mathrm{R}$ & $\mathrm{W}$ & $\mathrm{R}$ & $\mathrm{W}$ & $\mathrm{R}$ & $\mathrm{W}$ & $\mathrm{R}$ & $\mathrm{W}$ \\
\hline & 1 & 32 & 46 & 22 & 52 & 28 & 47 & 82 & 145 \\
\hline & & \multicolumn{2}{|c|}{ Task 1} & \multicolumn{2}{|c|}{ Task 3} & \multicolumn{2}{|c|}{ Task 2} & $36 \%$ & $64 \%$ \\
\hline & & $\mathrm{R}$ & $\mathrm{W}$ & $\mathrm{R}$ & $\mathrm{W}$ & $\mathrm{R}$ & $\mathrm{W}$ & $\mathrm{R}$ & $\mathrm{W}$ \\
\hline \multirow[t]{2}{*}{$=$} & 2 & 35 & 43 & 33 & 41 & 11 & 64 & 79 & 148 \\
\hline & & \multicolumn{2}{|c|}{ Task 2} & \multicolumn{2}{|c|}{ Task 1} & \multicolumn{2}{|c|}{ Task 3} & $35 \%$ & $65 \%$ \\
\hline \multirow[t]{6}{*}{$\simeq$} & & $\mathrm{R}$ & $\mathrm{W}$ & $\mathrm{R}$ & $\mathrm{W}$ & $\mathrm{R}$ & $\mathrm{W}$ & $\mathrm{R}$ & $\mathrm{W}$ \\
\hline & 3 & 27 & 51 & 33 & 41 & 27 & 48 & 87 & 140 \\
\hline & & \multicolumn{2}{|c|}{ Task 3} & \multicolumn{2}{|c|}{ Task 2} & \multicolumn{2}{|c|}{ Task 1} & $38 \%$ & $62 \%$ \\
\hline & & $\mathrm{R}$ & $\mathrm{W}$ & $\mathrm{R}$ & $\mathrm{W}$ & $\mathrm{R}$ & $\mathrm{W}$ & $\mathbf{R}$ & $\mathbf{W}$ \\
\hline & $\sum$ & 94 & 140 & 88 & 134 & 66 & 159 & 248 & 433 \\
\hline & & $40 \%$ & $60 \%$ & $40 \%$ & $60 \%$ & $29 \%$ & $71 \%$ & $36 \%$ & $64 \%$ \\
\hline
\end{tabular}

$\mathrm{R}=\mathrm{Right}$ (in the sense of a rational decision with correct use of Bayes' rule); $\mathrm{W}=$ Wrong (the decision follows a private signal).

What further aggravates the situation is that of the 248 right decisions, only a minority are accompanied by a correct reason for the decision. Table 4 summarizes the methods of solution given by those subjects who made "right" decisions. It becomes obvious that less than a quarter of the right decisions are based on the right rationale. For about $40 \%$ of the right decisions either faulty, nonsensical or no methods were given. Approximately every tenth person stated that they only guessed. About a quarter of the correct decisions are based on simplifying thumb rules: around $10 \%$ of the subjects are oriented towards the a priori probability, and $15 \%$ just decide as the majority of their predecessors did. 
Table 4

Explanations given by subjects for the 248 "right" decisions

\begin{tabular}{lcc}
\hline Methods given to arrive at the "right" decisions & Number & Percentage \\
\hline $\begin{array}{l}\text { Right method (inferring the private signals of the predecessors } \\
\text { and correct use of Bayes' rule) }\end{array}$ & 58 & $23.4 \%$ \\
Faulty use of Bayes' rule / nonsensical or incomprehensible & 88 & $35.5 \%$ \\
methods & 12 & $4.8 \%$ \\
No method given as to how the stated solution was arrived at & 26 & $10.5 \%$ \\
Guessed & 38 & $15.3 \%$ \\
Decision according to the majority decision of the predecessors & 26 & $10.5 \%$ \\
Decision according to the a priori probability & & \\
\hline
\end{tabular}

Only about $36 \%$ of the decisions are made according to the postulate of "Bayesian" informational cascades. Of these $36 \%$ about three quarters of the decisions are made for the wrong reasons and are therefore only accidentally correct. Regarding the whole population this means that not even every tenth decision is a correct one based on the correct reasons.

As $64 \%$ of all decisions correspond to the person's own private signals, and although this could in no case lead to the right decision (and thus to a reward), it must be presumed that a large part of the decision making was excessively influenced by own private signals. The present study results confirm the explanatory approach of Huck and Oechssler.

Examination of the number of correct decisions per participant permits further insights (Figure 1). $41 \%$ of the subjects followed their own private signal in all three situations. Around $45 \%$ of the subjects gave both right and wrong answers. Only around $13 \%$ of the participants solved all three tasks correctly. Median results (one or two right decisions) were only obtained by persons who neither systematically followed their own private signal nor made consistently rational decisions. These are the persons who guessed or who followed irrational thumb rules that purely coincidentally lead to success or failure. However, it is also possible to obtain three correct or three incorrect answers with random decisions. In the case of three decisions with two alternative answers each, only three-fourths of the subjects who simply guess or make random decisions attain a median result (one or two right decisions). If 
this is taken into account, it is revealed that around $60 \%(7.6 \%+23.1 \%+22.3 \%+7.6 \%)$ of subjects tend towards decisions made at random, about a third always follow their own private signal, and only around $6 \%$ make systematic rational decisions.

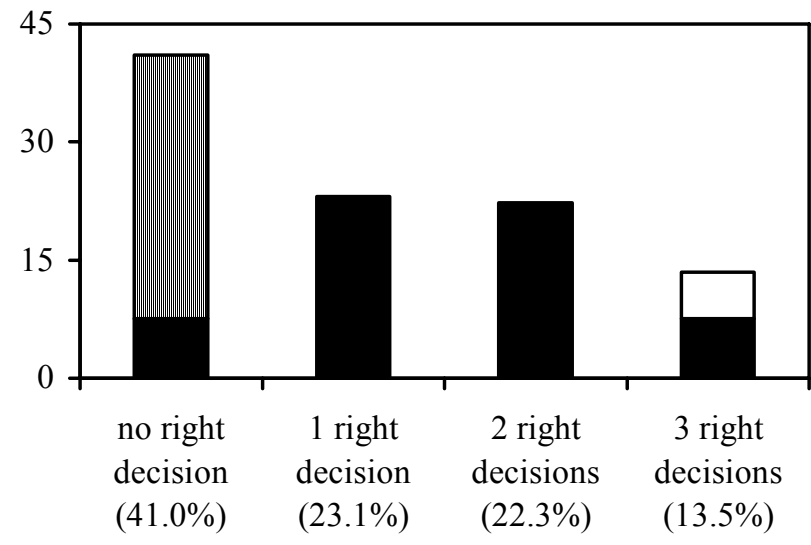

$\square$ Strategy "Bayes Rule" (5.9\%)

四 Strategy "Private Signal" (33.4\%)

- Random Decisions $(60.6 \%)$

Fig. 1. Classification of the subjects into four groups according to their level of success

Further results stress that it cannot be assumed that subjects act in a consistently rational manner:

1. A review of the three groups that had to solve the tasks in varying orders shows significantly varying success rates (see Table 3). While the results of group 1 (order: Task 1 , Task 2, Task 3) and group 2 (order: Task 3, Task 1, Task 2) are almost exactly alike (success rate $40 \%$ ), group 3 (order: Task 2, Task 3, Task 1) achieved a success rate of only $29 \%$. Such considerable variations of the success rate, which solely result from varying task orders, are no indication of rational decision making behavior by the subjects.

2. The three tasks do not have corresponding success rates. As can be seen in Table 5, Task 3 is solved in only $26 \%$ of all cases, while Task 1 and 2 are solved correctly in more than $40 \%$. This clear difference between the success rates does not indicate that the subjects are willing and able to apply Bayes' rule appropriately to concrete decision-making situations (in potential "Bayesian" informational cascades), although they fundamentally manage the necessary procedures of probability calculation. 
Table 5

Different success rates of the three tasks

\begin{tabular}{ccccccc}
\hline & \multicolumn{2}{c}{ Task 1 } & \multicolumn{2}{c}{ Task 2 } & \multicolumn{2}{c}{ Task 3 } \\
\hline Group & $\mathrm{R}$ & $\mathrm{W}$ & $\mathrm{R}$ & $\mathrm{W}$ & $\mathrm{R}$ & $\mathrm{W}$ \\
\hline 1 & 32 & 46 & 35 & 43 & 27 & 51 \\
2 & 33 & 41 & 33 & 41 & 22 & 52 \\
3 & 27 & 48 & 28 & 47 & 11 & 64 \\
\hline \multirow{2}{*}{$\Sigma$} & 92 & 135 & 96 & 131 & 60 & 167 \\
& $41 \%$ & $59 \%$ & $42 \%$ & $58 \%$ & $26 \%$ & $74 \%$ \\
\hline
\end{tabular}

$\mathrm{R}=\mathrm{Right}$ (in the sense of a rational decision with correct use of Bayes' rule); $\mathrm{W}=$ Wrong (the decision follows a private signal).

3. In the sixth and last session with 15 students (who already have an engineering degree and are presently completing postgraduate business administration studies comparable to an MBA), the ban on communication is lifted. The students receive the three tasks and have to hand in the solutions to the experimenter 36 hours later. Interchange is explicitly allowed, and the consultation of textbooks or expert opinions is not forbidden. When some of the participants are not intellectually up to the task but still strive for the best possible rational decision, it can be expected that they will use the time to gather information and to make the correct decisions. As can be seen from Table 6 the success rates are surprisingly similar to those of the rest of the study: $38 \%$ of all tasks were answered correctly, and for $62 \%$ of all tasks wrong answers were given. Obviously the decisions are based on different decisionmaking preferences than the "Bayesian" informational cascades suggest. The majority of the subjects do not seem to look for rational, best possible decisions by applying Bayes' rule. 
Table 6

The results of the six sessions

\begin{tabular}{lcccccc}
\hline Session & I & II & III & IV & V & VI \\
\hline Number of correct answers & 57 & 60 & 51 & 35 & 28 & 17 \\
Number of false answers & 108 & 90 & 87 & 76 & 44 & 28 \\
\hline Percentage of correct answers & $35 \%$ & $40 \%$ & $38 \%$ & $32 \%$ & $39 \%$ & $38 \%$ \\
Percentage of false answers & $65 \%$ & $60 \%$ & $62 \%$ & $68 \%$ & $61 \%$ & $62 \%$ \\
\hline
\end{tabular}

Session I: 55 undergraduate students; session II: 50 graduate students; session III: 46 undergraduate students; session IV: 37 graduate students; session V: 24 undergraduate and graduate students; session VI: 15 postgraduate students (corresponds to MBA).

A certain amount of variation in the six sessions can be clearly seen (Table 6). The percentage of correct answers varies between $32 \%$ in session IV and $40 \%$ in session II, but no session provides a majority of correct solutions. There is no indication that the contradiction between Anderson and Holt's and Huck and Oechssler's results can be explained by accidental, biasing peculiarities of the subject populations.

Therefore, the present results in no way support the estimation that "Bayesian" informational cascades can occur in reality. In the end, the model of "Bayesian" informational cascades only works when the successors can be sure that their predecessors have made rational decisions. However, the results of the study show that one certainly can not assume that all predecessors have made rational decisions. Kübler and Weizsäcker (2004) reveal that the successors do not really rely on their predecessors. In their study, the subjects (in contrast to this study) are left in the dark as to whether their predecessors made rational decisions or not. It turns out that the subjects always believe their predecessors to be less capable of rational decisions than themselves. $^{7}$

\footnotetext{
${ }^{7}$ More recent studies have shown that noisy behavior of the other subjects can frequently lead to considerable deviations from rational decision-making; see Goeree and Holt (1999, 2004). However, this does not explain the results presented here, as all the subjects were very clearly informed that all predecessors had made perfectly rational decisions. These newer studies do, however, emphasise existing doubts about whether informational cascades can genuinely occur in reality. Real decision-making situations are namely characterized by noisy behavior of the other subjects.
} 


\section{Conclusion}

The contradictory results of the experimental studies of Anderson and Holt and of Huck and Oechssler were the point of departure for this study. A total of 227 subjects were confronted with decision-making situations that permit a clear differentiation between orientation towards rationale and orientation towards the person's own private signal.

Of the total number of 681 decisions, only $248(36 \%)$ were based on rationale. Of these 248 decisions only 58 were made for the right reasons. For the other 190 correct decisions it became obvious that the subjects had either decided by simplifying irrational thumb rules, had only guessed, or were not able to sketch a comprehensible way to the solution. Similarly, in 433 decision-making situations $(64 \%)$ the participants made decisions that were contrary to the rational solution and in favor of their private signal.

Further results indicate that subjects are rarely willing to calculate the probabilities and then make a rational decision: 1 . the order in which the tasks are presented influences the results, 2. the degree to which the subjects successfully deal with the three decision-making situations varies considerably, and 3 . the success rates are not increased by the lifting of the communication ban and the possibility to refer to text books and expert opinions.

The urge to decide by simplifying thumb rules is obviously very strong, at least for these kinds of decision-making situations. Only a small number $(<6 \%)$ of the subjects systematically made a rational decision, considered all probabilities, and correctly applied Bayes' rule.

In some decision-making situations, one can obtain very good results by simplifying thumb rules or just by guessing. ${ }^{8}$ This type of behavior can therefore sometimes even be meaningful, if one considers that finding the right solution can be rather strenuous. In this experiment,

\footnotetext{
${ }^{8}$ Huck et al. $(2003,2004)$, for example, show that in a sequence of decision-making situations, subjects can come very close to the optimal solution with simple trial and error strategies without having recognized the background to the decision-making situation and thus the systematic way to reach a solution.
} 
however, the subjects face considerable disadvantages. Those who simply guess lose an average of half of their "fee" ( 7.5 bonus points $\approx € 36.23)$. Those who always follow their private signal actually lose their whole compensation ( 15 bonus points $\approx € 72.45$ ). On average for all subjects, just under two thirds of their possible bonus is lost $(9.58$ bonus points $\approx €$ 46.30). The use of simplifying thumb rules or pure guesswork therefore involves significant losses. The fact that the subjects accept these losses indicates that their preference for the use of simplifying thumb rules is highly developed.

This study confirms the results of Huck and Oechssler. The results of Anderson and Holt, however, will presumably have to be reinterpreted: if a number of subjects have to make decisions against the background of one private signal and their observation of the decisions of their predecessors, undoubtedly decision sequences emerge that look like "Bayesian" informational cascades. Then, however, one needs to examine whether the subjects have consistently made rational decisions or not.

Table 7

Banerjee's restaurant example

\begin{tabular}{llllllll}
\hline Subject & 1 & 2 & 3 & 4 & 5 & 6 & 7 \\
\hline Private signal & $b$ & $a$ & $a$ & $a$ & $a$ & $a$ & $a$ \\
Decision & $B$ & $B$ & $B$ & $B$ & $B$ & $B$ & $B$ \\
\hline
\end{tabular}

With an a priori probability for $\beta=0.51$ and for $\alpha=0.49$.

When a laboratory experiment leads to a situation such as the one given in Table 7 one may not simply infer the existence of a "Bayesian" informational cascade. Maybe subjects 2 and 3 decide merely upon the a priori probability, subjects 4 and 5 only according to the majority of their predecessors, and subjects 6 and 7 possibly only guess and hope to luck out and make a favorable decision. What then looks like a sequence of rational decisions derived by observing the actions of the predecessors, by drawing conclusions about their private signals, 
and correctly using Bayes' rule is in reality nothing more than an ostensible "Bayesian" informational cascade. 


\section{Appendix A. Text of the Tasks}

Task 3:

You must decide between alternative actions $A$ and $B$. When you make the right decision you will get 5 bonus points for the exam.

To begin with, action $A$ is right in $49 \%$ of all cases, and action $B$ is right in $51 \%$ of all cases.

Before you have to make your decision you will receive a hint (either " $a$ " or " $b$ ") towards the right action. This hint reveals the correct action to you in 65 out of 100 cases. ${ }^{9}$ This means: should you receive the hint " $b$ ", in 65 out of 100 cases action $B$ is the right one.

Other persons before you were confronted with this decision making situation. Person 1 had to make his decision first, then person 2, and so forth. Each person could see the decision their predecessors made, but not the hints these persons received. You know that the reliability of the hints for the persons before you was only $60 \% .{ }^{10}$ This means: should one of these persons for example receive hint " $b$ ", in only 60 out of 100 cases is action $B$ correct. All participants receive exactly one hint. The hints are independent of each other. All persons who already made their decision made a rational decision.

You are the third person to decide. The two predecessors decided thus: $A A$

You receive hint " $b$ ". ${ }^{11}$

Which action should you now choose?

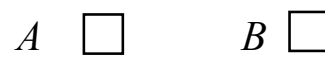

Please briefly explain upon which rationale you based your decision, or which way, if at all, you went about resolving this problem. These explanations have no influence on the granting of bonus points for the exam, therefore you should give an open and honest answer here!

\footnotetext{
${ }^{9}$ Task 1: 80 out of 100 cases; Task 2: 65 out of 100 cases.

${ }^{10}$ Task 1: also 80\%; Task 2: also $65 \%$.

${ }^{11}$ Task 1: You are the second person to decide. The person before you chose action $B$. You receive hint " $a$ "; Task 2: You are the $4^{\text {th }}$ person to decide. The three predecessors decided thus: $A B B$. You receive hint " $a$ ".
} 


\section{Appendix B. Detailed results of the six sessions}

Table 8

Session I: 55 undergraduate students

\begin{tabular}{|c|c|c|c|c|c|c|c|c|c|}
\hline & & & G & $\mathrm{r}$ & & $\mathrm{p}$ & & & \\
\hline & & \multicolumn{2}{|c|}{1} & \multicolumn{2}{|c|}{2} & \multicolumn{2}{|c|}{3} & \multicolumn{2}{|c|}{$\sum$} \\
\hline \multirow{4}{*}{$=$} & & $\mathrm{R}$ & $\mathrm{W}$ & $\mathrm{R}$ & $\mathrm{W}$ & $\mathrm{R}$ & $\mathrm{W}$ & $\mathrm{R}$ & $\mathrm{W}$ \\
\hline & 1 & 6 & 13 & 5 & 13 & 5 & 13 & 16 & 39 \\
\hline & & \multicolumn{2}{|c|}{ Task 1} & \multicolumn{2}{|c|}{ Task 3} & \multicolumn{2}{|c|}{ Task 2} & $29 \%$ & $71 \%$ \\
\hline & & $\mathrm{R}$ & $\mathrm{W}$ & $\mathrm{R}$ & $\mathrm{W}$ & $\mathrm{R}$ & $\mathrm{W}$ & $\mathrm{R}$ & $\mathrm{W}$ \\
\hline \multirow[t]{2}{*}{$=$} & 2 & 10 & 9 & 7 & 11 & 0 & 18 & 17 & 38 \\
\hline & & \multicolumn{2}{|c|}{ Task 2} & \multicolumn{2}{|c|}{ Task 1} & \multicolumn{2}{|c|}{ Task 3} & $31 \%$ & $69 \%$ \\
\hline \multirow[t]{6}{*}{$\simeq$} & & $\mathrm{R}$ & $\mathrm{W}$ & $\mathrm{R}$ & $\mathrm{W}$ & $\mathrm{R}$ & $\mathrm{W}$ & $\mathrm{R}$ & $\mathrm{W}$ \\
\hline & 3 & 7 & 12 & 10 & 8 & 7 & 11 & 24 & 31 \\
\hline & & \multicolumn{2}{|c|}{ Task 3} & \multicolumn{2}{|c|}{ Task 2} & \multicolumn{2}{|c|}{ Task 1} & $44 \%$ & $56 \%$ \\
\hline & & $\mathrm{R}$ & $\mathrm{W}$ & $\mathrm{R}$ & $\mathrm{W}$ & $\mathrm{R}$ & $\mathrm{W}$ & $\mathrm{R}$ & $\mathrm{W}$ \\
\hline & $\sum$ & 23 & 34 & 22 & 32 & 12 & 42 & 57 & 108 \\
\hline & & $40 \%$ & $60 \%$ & $41 \%$ & $59 \%$ & $22 \%$ & $78 \%$ & $35 \%$ & $65 \%$ \\
\hline
\end{tabular}

$\mathrm{R}=$ Right (in the sense of a rational decision made by correctly applying Bayes' Rule); W = Wrong (that means that the decision follows the person's private signal).

Table 9

Session II: 50 graduate students

\begin{tabular}{|c|c|c|c|c|c|c|c|c|c|}
\hline & & & G & r & & $\mathrm{p}$ & & & \\
\hline & \multicolumn{3}{|c|}{1} & \multicolumn{2}{|c|}{2} & \multicolumn{2}{|c|}{3} & \multicolumn{2}{|c|}{$\sum$} \\
\hline \multirow{4}{*}{$=$} & \multirow{3}{*}{1} & $\mathrm{R}$ & $\mathrm{W}$ & $\mathrm{R}$ & W & $\mathrm{R}$ & W & $\mathrm{R}$ & $\mathrm{W}$ \\
\hline & & 10 & 6 & 3 & 14 & 8 & 9 & 21 & 29 \\
\hline & & \multicolumn{2}{|c|}{ Task 1} & \multicolumn{2}{|c|}{ Task 3} & \multicolumn{2}{|c|}{ Task 2} & $42 \%$ & $58 \%$ \\
\hline & & $\mathrm{R}$ & W & $\mathrm{R}$ & W & $\mathrm{R}$ & $\mathrm{W}$ & $\mathrm{R}$ & $\mathrm{W}$ \\
\hline \multirow[t]{2}{*}{$=$} & 2 & & 7 & 6 & 11 & 5 & 12 & 20 & 30 \\
\hline & & \multicolumn{2}{|c|}{ Task 2} & \multicolumn{2}{|c|}{ Task 1} & \multicolumn{2}{|c|}{ Task 3} & $40 \%$ & $60 \%$ \\
\hline \multirow[t]{6}{*}{$\simeq$} & \multirow{3}{*}{3} & $\mathrm{R}$ & W & $\mathrm{R}$ & $\mathrm{W}$ & $\mathrm{R}$ & W & $\mathrm{R}$ & $\mathrm{W}$ \\
\hline & & 8 & 8 & 6 & 11 & 5 & 12 & 19 & 31 \\
\hline & & \multicolumn{2}{|c|}{ Task 3} & \multicolumn{2}{|c|}{ Task 2} & \multicolumn{2}{|c|}{ Task 1} & $38 \%$ & $62 \%$ \\
\hline & \multirow{3}{*}{$\sum$} & $\mathrm{R}$ & W & $\mathrm{R}$ & W & $\mathrm{R}$ & W & $\mathrm{R}$ & $\mathrm{W}$ \\
\hline & & 27 & 21 & 15 & 36 & 18 & 33 & 60 & 90 \\
\hline & & $56 \%$ & $44 \%$ & $29 \%$ & $71 \%$ & $35 \%$ & $65 \%$ & $40 \%$ & $60 \%$ \\
\hline
\end{tabular}

$\mathrm{R}=$ Right (in the sense of a rational decision made by correctly applying Bayes' Rule); W = Wrong (that means that the decision follows the person's private signal). 
Table 10

Session III: 46 undergraduate students

\begin{tabular}{|c|c|c|c|c|c|c|c|c|c|}
\hline & & & G & $\mathrm{r}$ & & $\mathrm{p}$ & & & \\
\hline & & \multicolumn{2}{|c|}{1} & \multicolumn{2}{|c|}{2} & \multicolumn{2}{|c|}{3} & \multicolumn{2}{|c|}{$\sum$} \\
\hline \multirow{4}{*}{$=$} & & $\mathrm{R}$ & $\mathrm{W}$ & $\mathrm{R}$ & $\mathrm{W}$ & $\mathrm{R}$ & $\mathrm{W}$ & $\mathrm{R}$ & $\mathrm{W}$ \\
\hline & 1 & 6 & 10 & 7 & 8 & 4 & 11 & 17 & 29 \\
\hline & & \multicolumn{2}{|c|}{ Task 1} & \multicolumn{2}{|c|}{ Task 3} & \multicolumn{2}{|c|}{ Task 2} & $37 \%$ & $63 \%$ \\
\hline & & $\mathrm{R}$ & $\mathrm{W}$ & $\mathrm{R}$ & $\mathrm{W}$ & $\mathrm{R}$ & $\mathrm{W}$ & $\mathrm{R}$ & $\mathrm{W}$ \\
\hline \multirow[t]{2}{*}{$=$} & 2 & 7 & 9 & 7 & 8 & 2 & 13 & 16 & 30 \\
\hline & & \multicolumn{2}{|c|}{ Task 2} & \multicolumn{2}{|c|}{ Task 1} & \multicolumn{2}{|c|}{ Task 3} & $35 \%$ & $65 \%$ \\
\hline \multirow[t]{6}{*}{$\simeq$} & & $\mathrm{R}$ & $\mathrm{W}$ & $\mathrm{R}$ & $\mathrm{W}$ & $\mathrm{R}$ & $\mathrm{W}$ & $\mathrm{R}$ & $\mathrm{W}$ \\
\hline & 3 & 4 & 12 & 6 & 9 & 8 & 7 & 18 & 28 \\
\hline & & \multicolumn{2}{|c|}{ Task 3} & \multicolumn{2}{|c|}{ Task 2} & \multicolumn{2}{|c|}{ Task 1} & $39 \%$ & $61 \%$ \\
\hline & & $\mathrm{R}$ & $\mathrm{W}$ & $\mathrm{R}$ & $\mathrm{W}$ & $\mathrm{R}$ & $\mathrm{W}$ & $\mathrm{R}$ & $\mathrm{W}$ \\
\hline & $\sum$ & 17 & 31 & 20 & 25 & 14 & 31 & 51 & 87 \\
\hline & & $35 \%$ & $65 \%$ & $44 \%$ & $56 \%$ & $31 \%$ & $69 \%$ & $38 \%$ & $62 \%$ \\
\hline
\end{tabular}

$\mathrm{R}=$ Right (in the sense of a rational decision made by correctly applying Bayes' Rule); $\mathrm{W}=$ Wrong (that means that the decision follows the person's private signal).

Table 11

Session IV: 37 graduate students

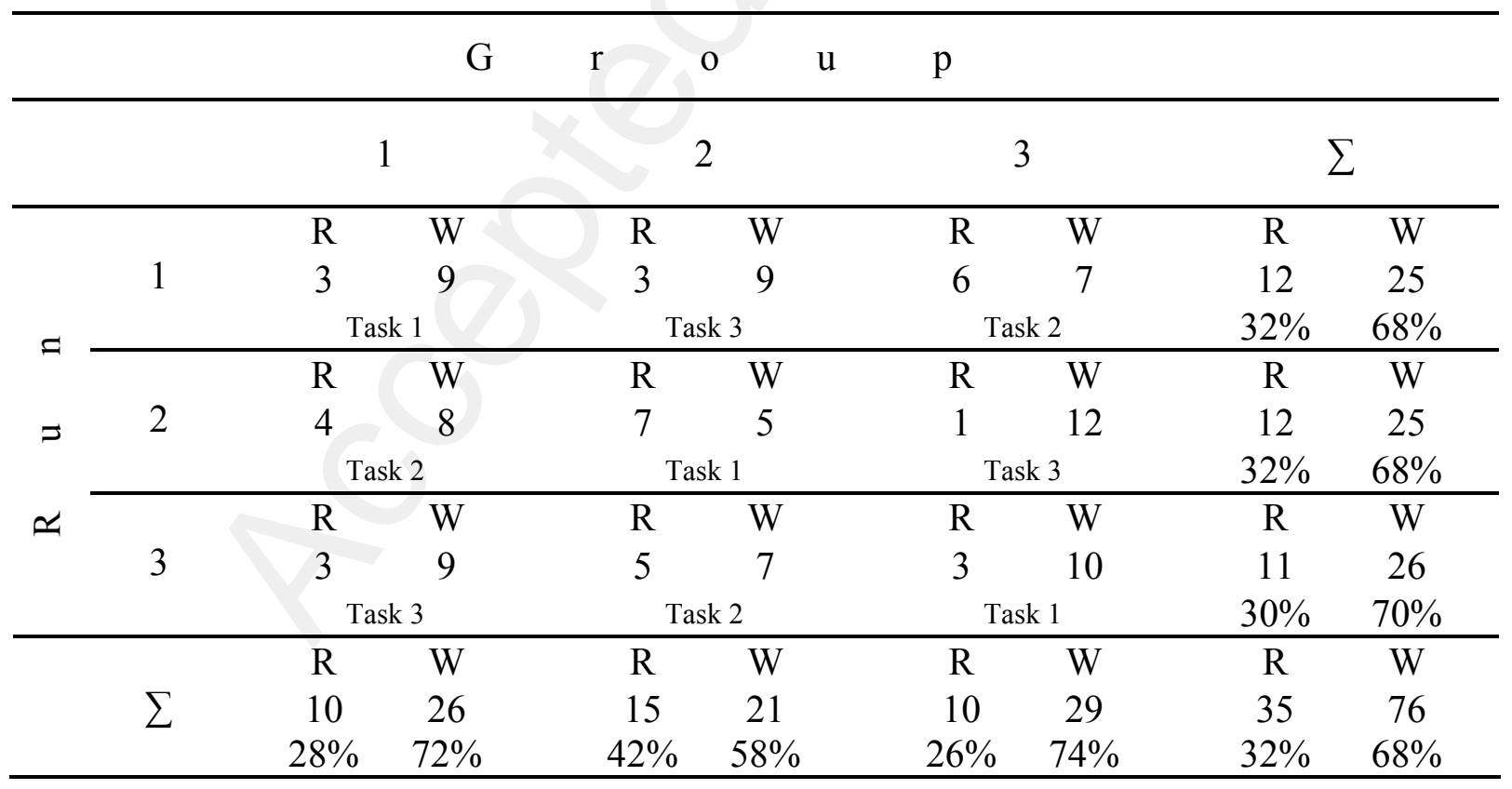

$\mathrm{R}=$ Right (in the sense of a rational decision made by correctly applying Bayes' Rule); W = Wrong (that means that the decision follows the person's private signal). 
Table 12

Session V: 24 undergraduate and graduate students

\begin{tabular}{|c|c|c|c|c|c|c|c|c|c|}
\hline & & & G & $\mathrm{r}$ & & $\mathrm{p}$ & & & \\
\hline & & \multicolumn{2}{|c|}{1} & \multicolumn{2}{|c|}{2} & \multicolumn{2}{|c|}{3} & \multicolumn{2}{|c|}{$\sum$} \\
\hline \multirow{4}{*}{$=$} & & $\mathrm{R}$ & W & $\mathrm{R}$ & W & $\mathrm{R}$ & W & $\mathrm{R}$ & W \\
\hline & 1 & 5 & 5 & 3 & 4 & 3 & 4 & 11 & 13 \\
\hline & & \multicolumn{2}{|c|}{ Task 1} & \multicolumn{2}{|c|}{ Task 3} & \multicolumn{2}{|c|}{ Task 2} & $46 \%$ & $54 \%$ \\
\hline & & $\mathrm{R}$ & $\mathrm{W}$ & $\mathrm{R}$ & $\mathrm{W}$ & $\mathrm{R}$ & $\mathrm{W}$ & $\mathrm{R}$ & $\mathrm{W}$ \\
\hline \multirow[t]{2}{*}{$=$} & 2 & 3 & 7 & 4 & 3 & 2 & 5 & 9 & 15 \\
\hline & & \multicolumn{2}{|c|}{ Task 2} & \multicolumn{2}{|c|}{ Task 1} & \multicolumn{2}{|c|}{ Task 3} & $37 \%$ & $63 \%$ \\
\hline \multirow[t]{6}{*}{$\simeq$} & & $\mathrm{R}$ & W & $\mathrm{R}$ & $\mathrm{W}$ & $\mathrm{R}$ & $\mathrm{W}$ & $\mathrm{R}$ & $\mathrm{W}$ \\
\hline & 3 & 2 & 8 & 4 & 3 & 2 & 5 & 8 & 16 \\
\hline & & \multicolumn{2}{|c|}{ Task 3} & \multicolumn{2}{|c|}{ Task 2} & \multicolumn{2}{|c|}{ Task 1} & $33 \%$ & $67 \%$ \\
\hline & & $\mathrm{R}$ & $\mathrm{W}$ & $\mathrm{R}$ & $\mathrm{W}$ & $\mathrm{R}$ & $\mathrm{W}$ & $\mathrm{R}$ & $\mathrm{W}$ \\
\hline & $\sum$ & 10 & 20 & 11 & 10 & 7 & 14 & 28 & 44 \\
\hline & & $33 \%$ & $67 \%$ & $52 \%$ & $48 \%$ & $33 \%$ & $67 \%$ & $39 \%$ & $61 \%$ \\
\hline
\end{tabular}

$\mathrm{R}=$ Right (in the sense of a rational decision made by correctly applying Bayes' Rule); $\mathrm{W}=$ Wrong (that means that the decision follows the person's private signal).

Table 13

Session VI: 15 postgraduate students (corresponds to an MBA) with no order of the tasks, with the possibility to communicate among the subjects, and handing in after 36 hours maximum to work on it.

\begin{tabular}{|c|c|c|c|c|c|c|c|c|c|}
\hline & & & G & $\mathrm{r}$ & & $\mathrm{p}$ & & & \\
\hline & & \multicolumn{2}{|c|}{1} & \multicolumn{2}{|c|}{2} & \multicolumn{2}{|c|}{3} & \multicolumn{2}{|c|}{$\sum$} \\
\hline \multirow{4}{*}{$=$} & & $\mathrm{R}$ & W & $\mathrm{R}$ & $\mathrm{W}$ & $\mathrm{R}$ & W & $\mathrm{R}$ & W \\
\hline & 1 & 2 & 3 & 1 & 4 & 2 & 3 & 5 & 10 \\
\hline & & \multicolumn{2}{|c|}{ Task 1} & \multicolumn{2}{|c|}{ Task 3} & \multicolumn{2}{|c|}{ Task 2} & $33 \%$ & $67 \%$ \\
\hline & & $\mathrm{R}$ & W & $\mathrm{R}$ & $\mathrm{W}$ & $\mathrm{R}$ & $\mathrm{W}$ & $\mathrm{R}$ & $\mathrm{W}$ \\
\hline \multirow[t]{2}{*}{$=$} & 2 & 2 & 3 & 2 & 3 & 1 & 4 & 5 & 10 \\
\hline & & \multicolumn{2}{|c|}{ Task 2} & \multicolumn{2}{|c|}{ Task 1} & \multicolumn{2}{|c|}{ Task 3} & $33 \%$ & $67 \%$ \\
\hline \multirow[t]{6}{*}{$\simeq$} & & $\mathrm{R}$ & $\mathrm{W}$ & $\mathrm{R}$ & $\mathrm{W}$ & $\mathrm{R}$ & $\mathrm{W}$ & $\mathrm{R}$ & $\mathrm{W}$ \\
\hline & 3 & & 2 & 2 & 3 & 2 & 3 & 7 & 8 \\
\hline & & \multicolumn{2}{|c|}{ Task 3} & \multicolumn{2}{|c|}{ Task 2} & \multicolumn{2}{|c|}{ Task 1} & $47 \%$ & $53 \%$ \\
\hline & & $\mathrm{R}$ & $\mathrm{W}$ & $\mathrm{R}$ & $\mathrm{W}$ & $\mathrm{R}$ & $\mathrm{W}$ & $\mathrm{R}$ & $\mathrm{W}$ \\
\hline & $\sum$ & 7 & 8 & 5 & 10 & 5 & 10 & 17 & 28 \\
\hline & & $47 \%$ & $53 \%$ & $33 \%$ & $67 \%$ & $33 \%$ & $67 \%$ & $38 \%$ & $62 \%$ \\
\hline
\end{tabular}

$\mathrm{R}=$ Right (in the sense of a rational decision made by correctly applying Bayes' Rule); $\mathrm{W}=$ Wrong (that means that the decision follows the person's private signal). 


\section{Appendix C. Detailed ways of solution of the three tasks}

Task 1: The only predecessor chose $B$; thus the conclusion is that his private signal was $b$. The subject receives the private signal $a$. The two private signals neutralize each other, so the decision must be based on the a priori probability. Therefore action $B$ is the right one.

Task 2: The first predecessor chose $A$, from which it follows that his private signal is $a$. The second predecessor chose $B$, which hints at $b$ as his private signal. The third predecessor has obviously also received signal $b$ because had he received $a, A$ would have been the rational decision (two $a$ 's would have exceeded $b$ with a reliability of the signals of 0.65 , even when the a priori probability speaks for $B$ ). Now the student receives signal $a$. He must note that the private signals of his predecessors and his own private signal exactly neutralize each other (two $a$ 's and two $b$ 's). Therefore the subject again has to orient himself towards the a priori probability, which speaks for action $B$.

Task 3: It is necessary to calculate the more probable of the two alternative actions.

$\begin{array}{lll}\alpha, \beta & =\text { States of the world } & \operatorname{prob}(\alpha \mid a)=0.60 \\ \operatorname{prob}(\alpha) & =0.49 & \operatorname{prob}(\beta \mid a)=0.40 \\ \operatorname{prob}(\beta) & =0.51 & \operatorname{prob}(\alpha \mid b)=0.35 \\ a, b & =\text { Signals } & \operatorname{prob}(\beta \mid b)=0.65\end{array}$

$\operatorname{prob}(a \mid \alpha)=\frac{\operatorname{prob}(\alpha \mid a) \operatorname{prob}(\alpha)}{\operatorname{prob}(a)}$

$\operatorname{prob}(a) \quad=\operatorname{prob}(\alpha \mid a) * \operatorname{prob}(\alpha)+\operatorname{prob}(\beta \mid a) * \operatorname{prob}(\beta)$

$=0.60 * 0.49+0.40 * 0.51$

$=0.498$

$\operatorname{prob}(a \mid \alpha)=\frac{0.6 * 0.49}{0.498}=\frac{0.294}{0.498}=0.590361445$

$\operatorname{prob}(b \mid \alpha)=\frac{\operatorname{prob}(\alpha \mid b) \operatorname{prob}(\alpha)}{\operatorname{prob}(b)}$

$\operatorname{prob}(b) \quad=\operatorname{prob}(\alpha \mid b) * \operatorname{prob}(\alpha)+\operatorname{prob}(\beta \mid b) * \operatorname{prob}(\beta)$

$=0.35 * 0.49+0.65 * 0.51=0.503$ 
$\operatorname{prob}(b \mid \alpha)=\frac{0.35 * 0.49}{0.503}=\frac{0.1715}{0.503}=0.340954274$

$\operatorname{prob}(a \mid \beta)=\frac{0.4 * 0.51}{0.498}=\frac{0.204}{0.498}=0.409638554$

$\operatorname{prob}(b \mid \beta)=\frac{0.65 * 0.51}{0.503}=\frac{0.3315}{0.503}=0.659045725$

$\operatorname{prob}(\alpha \mid a a b)=\frac{\operatorname{prob}(a a b \mid \alpha) \operatorname{prob}(\alpha)}{\operatorname{prob}(a a b \mid \alpha) \operatorname{prob}(\alpha)+\operatorname{prob}(a a b \mid \beta) \operatorname{prob}(\beta)}$

$$
\begin{aligned}
& =\frac{(0.590361445)^{2} * 0.340954274 * 0.49}{(0.590361445)^{2} * 0.340954274 * 0.49+(0.409638554)^{2} * 0.659045725 * 0.51} \\
& =\frac{0.058227506}{0.058227506+0.056401073}=0.507966743
\end{aligned}
$$

The decision for alternative $A$ is the rational one, because it is more probable. 


\section{References}

Anderson, L.R., Holt, C.A., 1997. Information cascades in the laboratory. The American Economic Review 87, 847-862.

Banerjee, A.V., 1992. A simple model of herd behavior. The Quarterly Journal of Economics $107,797-817$

Bikhchandani, S., Hishleifer, D., Welch, I., 1992. A theory of fads, fashion, custom, and cultural change as informational cascades. Journal of Political Economy 100, 992-1026.

Celen, B., Kariv, S., 2004. Distinguishing information cascades from herd behavior in the laboratory. The American Economic Review 94, 484-498.

Goeree, J. K., Holt, C. A., 1999. Stochastic game theory: for playing games, not just for doing theory. Proceedings of the National Academy of Sciences 96, 10564-10567.

Goeree, J. K., Holt, C. A., 2004. A model of noisy introspection. Games and Economic Behavior 46, 365-382.

Huck, S., Oechssler, J., 2000. Informational cascades in the laboratory: do they occur for the right reasons? Journal of Economic Psychology 21, 661-671.

Huck, S., Normann, H.-T., Oechssler, J., 2003. Zero-knowledge cooperation in dilemma games. Journal of Theoretical Biology 220, 47-54.

Huck, S., Normann, H.-T., Oechssler, J., 2004. Through trial and error to collusion. International Economic Review 45, 205-224.

Hung, A.A., Plott, C.R., 2001. Information cascades: replication and an extension to majority rule and conformity-rewarding institutions. The American Economic Review 91, 15081520.

Keynes, J.M., 1936. The General Theory of Employment, Interest, and Money. London: Macmillan. 
Kübler, D., Weizsäcker, G., 2004. Limited depth of reasoning and failure of cascade formation in the laboratory. Review of Economic Studies 71, 425-441.

Selten, R., Abbink, K., Buchta, J., Sadrieh, A., 2003. How to play (3 x 3)-games. A strategy method experiment. Games and Economic Behavior 45, 19-37.

Sgroi, D., 2003. The right choice at the right time: a herding experiment in endogenous time. Experimental Economics 6, 159-180. 